\title{
The application of service robots for logistics in manufacturing processes
}

\author{
Karabegović, I. ${ }^{\mathrm{a},{ }^{*}}$, Karabegović, E. ${ }^{a}$, Mahmić, M. ${ }^{a}$, Husak, E. ${ }^{a}$ \\ a University of Bihać, Faculty of Technical Engineering, dr. Irfana Ljubijankića bb., Bihać, Bosnia and Herzegovina
}

\section{A B S T R A C T}

The introduction of service robots AGVs (automatic guided vehicles) into manufacturing processes is one of the more important qualitative shifts in the automation of transport operations in the manufacturing, assembly lines, as well as storages. Given the large number of applications, service robots in logistics offer a wide range of different technical and exploitative solutions. Service robots AGVs are primarily used for the realization of internal transport processes. Service logistics robots in the manufacturing processes have a very large estimate of the significance of factors when it comes to physical labour reduction. The investment in installing service robots is amortized much faster provided that the service robots work 24 hours a day. The investment in service robots for logistics is repaid within 2-3 years, and such a system works for about 15 years, operating costs are around 2-4 \% annual investment, operation availability is approximately $98.5 \%$, a high productivity, optimized costs and processing time. This paper presents the annual application of service robots in logistics, as well as applications of AGVs service robots with different structures in the manufacturing processes, in confined areas and open spaces, such as shipping containers in ports.
\end{abstract}

\section{ARTICLE INFO}

Keywords:

Service robots

Automatic guided vehicles

Logistics

Transportation

Manufacturing process

Assembly process

*Corresponding author: isak1910@hotmail.com (Karabegović, I.)

Article history:

Received 11 December 2014

Revised 5 April 2015

Accepted 7 September 2015 


\title{
Uporaba servisnih robotov za logistiko v proizvodnih postopkih
}

\author{
Karabegović, I. a, ${ }^{\text {, }}$, Karabegović, E. ${ }^{a}$, Mahmić, M. ${ }^{a}$, Husak, E. $^{a}$ \\ a University of Bihać, Faculty of Technical Engineering, dr. Irfana Ljubijankića bb., Bihać, Bosnia and Herzegovina
}

\section{POVZETEK}

Uvajanje servisnih robotov AGV (avtomatsko vodeni vozički) v proizvodne postopke je eden izmed najbolj pomembnih kakovostnih premikov za optimizacijo transportnih operacij pri proizvodnji in montažnih linijah ter tudi pri skladiščenju. Zaradi raznolikosti industrijskih opravil ponujajo servisni roboti široke možnosti uporabe in različnih tehničnih rešitev. Servisni roboti so bili primarno namenjeni za notranji transport. Z uporabo servisnih robotov se lahko bistveno zmanjša potreba po fizični delovni sili. Če servisni roboti delujejo 24 ur na dan se investicija hitro povrne, praviloma v času od dveh do treh let. Takšni servisni roboti za logistiko delujejo približno 15 let, stroški obratovanja so okoli 2-4 \% letne investicije, razpoložljivost je približno $98.5 \%$, so visoko produktivni, delujejo pa na optimalen način z vidika stroškov in časa obratovanja. V prispevku je prikazana uporaba servisnih robotov v logistiki, kakor tudi možnosti uporabe sistemov AGV v različnih proizvodnih okoljih, v zaprtih prostorih in tudi na prostem, kot je npr. uporaba teh sistemov za potrebe pristaniščnih kontejnerskih terminalov.

\section{PODATKI O ČLANKU}

Ključne besede: Servisni roboti

Avtomatsko voden voziček

Logistika

Transport

Proizvodni postopek

Montažni postopek

*Kontaktna oseba: isak1910@hotmail.com

(Karabegović, I.)

Zgodovina članka:

Prejet 11. decembra 2014

Popravljen 5. aprila 2015

Sprejet 7. septembra 2015 


\section{References}

[1] Karabegović, I., Doleček, V. (2012). Servisni roboti, Društvo za robotiku Bihać, Bihać, Bosnia and Herzegovina.

[2] Doleček ,V., Karabegović, I. (2002). Robotika, Tehnički fakultet Bihać, Bihać, Bosnia and Herzegovina.

[3] Bakšys, B., Fedaravičius, A. (2004). Robotu Technika, Kaunas Technologija, Kaunas, Lithuania.

[4] Buchmeister, B., Friscic, D., Palcic, I. (2013). Impact of demand changes and supply chain's level constraints on bullwhip effect, Advances in Production Engineering \& Management, Vol. 8, No. 4, 199-208.

[5] Dev Anand, M., Selvaraj, T., Kumanan, S., Ajith Bosco Raj, T. (2012). Robotics in online inspection and quality control using moment algorithm, Advances in Production Engineering \& Management, Vol. 7, No. 1, 27-38.

[6] Dev Anand, M., Selvaraj, T., Kumanan, S. (2012). Fault detection and fault tolerance methods for industrial robot manipulators based on hybrid intelligent approach, Advances in Production Engineering \& Management, Vol. 7, No. 4, 225-236.

[7] World Robotics (2013). United Nations, IFR Statistical Department, c/o VDMA Robotics + Automation, New York and Geneva.

[8] World Robotics (2011). United Nations, IFR Statistical Department, c/o VDMA Robotics + Automation, New York and Geneva.

[9] World Robotics (2010). United Nations, IFR Statistical Department, c/o VDMA Robotics + Automation, New York and Geneva.

[10] World Robotics (2008). United Nations, IFR Statistical Department, c/o VDMA Robotics + Automation, New York and Geneva.

[11] Rogić, M. (2001). Industrijski roboti, Mašinski fakultet Banjaluka, Banjaluka, Bosnia and Herzegovina.

[12] Wloka, D.W. (1992). Roboter sisteme 1, Springer-Verlag, Berlin Heidelberg, Germany.

[13] Freund, E., Stern, O. (1999). Robotertechnologie I, Institut für Roboterforschung, Dortmund, Germany.

[14] Karabegović, I., Doleček, V. (2014). Role of service robots in modernization of society of 21. century, In: Proceeding of New Technology NT-2014, Mostar, 27-38.

[15] Karabegović, I., Karabegović, E., Husak, E. (2013). Application of service robots in rehabilitation and support of patients, Medicina Fluminensis, Vol. 49, No. 2, 167-174.

[16] Karabegović, I., Karabegović, E., Husak E. (2012). Service robot application for examination and maintaining of water supply, gas and sewage systems, International Journal of Engineering Research and Development, Vol. 2, No. 4, 53-57.

[17] Karabegović, I., Husak, E., Đukanović, M. (2014). Aplikacija inteligentnih sistema-robota u proizvodnim procesima [Applications of intelligent systems-robots in the manufacturing processes], In: Zbornik radova sa 19. naučno-stručnog skupa Informacione Tehnologije - IT 2014, [Proceeding of the 19th Conference Information Tehnology - IT 2014], Faculty of Electrical, Engineering, University of Montenegro, Žabljak, 177-180.

[18] Robotnik. Robotic Engineering Projects and Services, from http://www.servicerobotics.info, accessed October 15, 2014.

[19] Neobotik. Transportation, from http://www.neobotix-robots.com/applications-transportation.html, accessed 18 October, 2014.

[20] LamsonGroup. Material Handling, from http://www.lamson.com.au/new/?page id=20\#transcar accessed October 20, 2014.

[21] The Robotics Institute. Field robotics center, from $h t t p: / / w w w . f r c . r i . c m u . e d u$ accessed November 1, 2014.

[22] The Hi-techroboticsystemz, from http://www.hitechroboticsystemz.com, accessed November 5, 2014.

[23] Robotics Business Review, from http://www.roboticsbusinessreview.com, accessed November 8, 2014.

[24] Unitronics, from $\underline{h t t p: / / w w w . i r o b . c o m . t r}$, accessed November 15, 2014.

[25] Siasun, from http://www.siasun.com accesseed December 1, 2014

[26] University of Southern Denmark, RoboLab, from http://www.sdu.dk/en/om_sdu/fakulteterne/teknik/forskning/ robolab, accessed December 1, 2014.

[27] Egemin Automation, from http://www.egemin-automation.com/en/, accessed December 5, 2014.

[28] Modern Materials Handling, from http://www.mmh.com/article/7_fresh_ways_to_think_about_agvs, accessed December 5, 2014.

[29] PortStrategy, from http://www.portstrategy.com, accessed December 8, 2014. 